\title{
BCG vaccination in the first year of life protects children of Indian subcontinent ethnic origin against tuberculosis in England
}

\author{
Laura C Rodrigues, O Noel Gill, Peter G Smith
}

\begin{abstract}
Study objective-The aim was to assess the protection conferred by BCG given during the first year of life against tuberculosis among children of Asian ethnic origin born in England.

Design-This was a matched case-control study.

Setting-Cases were selected from notifications of tuberculosis and controls were selected from child health or school health records in 14 English health districts.

Participants-111 cases of childhood tuberculosis with Asian names were selected. For each case there were five controls with Asian names, matched for age, sex and district of birth.

Measurements and main results-Child health or school health records were searched to determine the proportions of cases and controls who had been vaccinated with BCG. Overall, BCG vaccination given in the first year of life was estimated to confer $49 \%$ protection against tuberculosis with $95 \%$ confidence interval $14-62 \%$.

Conclusions-BCG vaccination in infancy was found to be associated with a lower protective efficacy than has been found for the secondary school age BCG programme $(80 \%)$ but nevertheless the protection is substantial and, in the United Kingdom, BCG vaccination of infants considered to be at relatively higher risk of tuberculosis is likely to reduce the incidence of childhood tuberculosis.
\end{abstract}

In a randomised controlled trial conducted by the Medical Research Council among children aged 13 to 14 years, BCG was found to confer about $80 \%$ protection against tuberculosis for up to 15 years after vaccination. ${ }^{1}$ BCG has been administered to adolescent schoolchildren in the UK since 1953 and in evaluations of this programme it has been found that the protective efficacy of vaccination has continued to be similar to that observed in the controlled trial. ${ }^{23}$ As the incidence of tuberculosis in the UK has declined, consideration has been given to stopping the universal school BCG programme and continuing with a selective vaccination policy. In 1972 it was recommended that BCG vaccination be given at birth to children born into immigrant communities with a high incidence of tuberculosis. ${ }^{4}$ Gradually, this policy was introduced to many health districts in the UK, especially those with a large immigrant population. Doubts about the effectiveness of
BCG in those of Asian ethnic group have been raised, however, by the findings in the large randomised trial of BCG vaccination in South India, in which BCG was found to offer little, if any, protection against tuberculosis. ${ }^{5}$ Although the few randomised trials of neonatal BCG vaccination have shown good protection, ${ }^{6}$ none of these was undertaken in people of Indian subcontinent ethnic group, and the South Indian trial did not include neonatal BCG vaccination. Estimates of protective efficacy conferred by BCG given early in life, derived from recent case-control studies, have varied from 0 to $80^{\circ}{ }_{0} .{ }^{7}$ Curtis et $a l^{8}$ reported a protective efficacy of about $75 \%$ associated with neonatal vaccination in Manchester, but this study included only three cases in children of Indian ethnic origin, and no conclusions could be drawn regarding this group. Because of the uncertainty regarding the efficacy of BCG for Asian children, we have conducted a national case-control study to assess the level of protection against tuberculosis that BCG vaccination, given at birth in England, has provided to children of Asian ethnic origin.

\section{Methods}

Thirty health districts were selected for potential inclusion in the study. These were chosen based on the number of cases of tuberculosis in persons of Indian subcontinent ethnic origin recorded in the 1976 and 1983 national tuberculosis surveys ${ }^{910}$ and on when (and whether) routine BCG vaccination of newborn babies in high risk groups was introduced (derived from vaccination programme annual returns).

Districts were included in the study from the time when more than 100 newborn BCG vaccinations were given annually and if they had at least one notification of tuberculosis in an Asian child who had been born after the local introduction of the newborn BCG programme. Four districts were unable to participate, principally due to delays with local ethical approval.

Eligible cases of tuberculosis were identified in each district by searching for children with Indian subcontinent surnames in the lists of tuberculosis notifications. Ethnic origin (Sikh, Hindi, Muslim) was assigned according to surname based on a list produced by the Office of Population Censuses and Surveys after the 1980 census. Clinical records were examined and children were excluded if they were not born in the UK, their diagnosis had been changed from tuberculosis, or if they had received only chemoprophylaxis (given to children who had been examined as a contact but who had no signs 
or symptoms of tuberculosis and had a normal $x$ ray). Records, including contact tracing records, were also examined to establish whether the case was originally vaccinated because of a known case of tuberculosis in the family or simply as part of the local programme. Information from the clinical records and contact tracing notes was abstracted to a standard form by one of us (LR).

Five controls were selected for each case from the district child health registry or, when this was not available, from school health records. The records were usually arranged in date of birth order and controls were selected for each case from children with Asian subcontinent surnames of the same sex, and with the nearest date of birth to the case, usually within a week. Specific ethnic origin (whether Sikh, Hindu or Muslim) was not matched for, but was subsequently controlled in the analysis. For the 11 cases who were born outside the district in which tuberculosis was diagnosed, controls were selected from among those who were also born outside the district. For the remaining cases, controls were selected from among those born in the same district as was each case. The history of BCG vaccination was taken, for cases and controls, from the child health registry or, when this was not available, from the school health records. The selection of controls and the abstraction of data on vaccination was undertaken by the same person (LR). The controls were selected before the vaccination records were abstracted and, in general, information on BCG vaccination was recorded in a standard place in the most child health records. Five cases were not found in the child health register and these were excluded.

After all exclusions, 14 districts contributed a total of 111 cases to the study. These districts were: Bolton (20 cases), Bradford (17), Brent (6), Dudley (6), Leicester (16), Manchester (8), Newham (6), Redbridge (6), Rochdale (5), Sandwell (7), Tameside (2), Walsall (2), Waltham Forest (3), and Wolverhampton (7). Birmingham, where a similar study was being conducted, was not included.

Children given BCG after tuberculosis had been diagnosed or, for controls, after the age of diagnosis of the matched case, were regarded as unvaccinated in the analysis.

Statistical analyses were conducted using conditional maximum likelihood methods, using the computer program EGRET. ${ }^{11}$

\section{Results}

The average age at diagnosis of cases included in the study was 4 years and 8 months, with a range from 8 months to 12 years. Sixty three cases were aged 5 years or less at diagnosis. The earliest case included was born in 1974 and the latest in 1987, and $77 \%$ were born in 1982 or later. Of the 111 cases included, 47 were girls. Thirty three of the cases had pulmonary tuberculosis or tuberculous pleural effusion, 71 had tuberculous adenitis (of these $\mathbf{5 2}$ had tuberculosis of the hilar glands), four had tuberculous meningitis, and three had tuberculosis of the bone. Forty five cases had been admitted to hospital for their disease. No skin test result had been recorded for 17, 66 were tuberculin sensitive (to Mantoux, Heaf or Tine), and 17 became sensitive to tuberculin during observation. The remaining 11 were not sensitive. No diagnostic bacteriological test was performed for 79 of the children, 19 had a positive culture, four had a positive smear, and nine had negative bacteriological tests. A slightly higher proportion of cases $\left(49^{\circ} \mathrm{o}\right)$ than of controls $\left(45^{\circ}{ }_{0}\right)$ had Moslem names or names that may have been Moslem. Fifty nine cases were diagnosed through contact tracing, 46 presented with symptoms, five were diagnosed while under investigation for another disease, and one was diagnosed in a school examination before routine BCG vaccination. The families of 10 of the cases had a member known to have tuberculosis before the birth of the case (information from contact tracing notes). The mothers of at least two of these children had been advised during pregnancy to have the child vaccinated soon after birth.

Only four children, all controls, had received more than one BCG vacination. Thirteen children (one case and 12 controls) were vaccinated after the first year of life. For those vaccinated during the first year, the average age at vaccination was 5 weeks, and $35^{\circ}$ o were vaccinated in the first week of life.

Overall, $51^{\circ}$ of the cases had received BCG prior to diagnosis, compared to $64^{\circ}{ }_{0}$ of the controls. In table I the BCG vaccination histories for each case and their matched controls are summarised. The maximum likelihood estimate of the relative risk of tuberculosis associated with BCG vaccination is $51^{\circ}$ o, corresponding to an estimate of protective efficacy of $49^{\circ}{ }_{0}\left(95^{\circ}{ }_{0}\right.$

Table I Distribution of cases of tuberculosis and matched quintuplet sets of controls by history of $B C G$ vaccination.

\begin{tabular}{|c|c|c|c|c|c|c|c|}
\hline \multirow{2}{*}{$\begin{array}{l}\text { Case with } \\
\text { history of } \\
\text { BCG }\end{array}$} & \multicolumn{6}{|c|}{$\begin{array}{l}\text { No of controls in set with } \\
\text { history of } B C G\end{array}$} & \multirow{2}{*}{$\begin{array}{l}\text { Total No } \\
\text { of sets }\end{array}$} \\
\hline & 0 & 1 & 2 & 3 & 4 & 5 & \\
\hline $\begin{array}{l}\text { No } \\
\text { Yes }\end{array}$ & $\begin{array}{r}11 \\
1\end{array}$ & $\begin{array}{r}15 \\
5\end{array}$ & $\begin{array}{r}11 \\
1\end{array}$ & $\begin{array}{l}5 \\
3\end{array}$ & $\begin{array}{r}7 \\
20\end{array}$ & $\begin{array}{r}5 \\
27\end{array}$ & $\begin{array}{l}54 \\
57\end{array}$ \\
\hline
\end{tabular}

Protective efficacy $=49^{\circ}{ }_{0} ; 95^{\circ}{ }_{0}$ confidence interval $=14^{\circ}{ }_{0}-70^{\circ}{ }_{0}$

confidence interval $14^{\circ}{ }_{0}$ to $70^{\circ}{ }_{0}$ ). Controlling for the differences in ethnic composition (Sikh, Hindu, Moslem) of the case and control groups made no material difference to the estimate of protective efficacy $=52^{\circ}{ }_{0}$. Estimates of protective efficacy were made for various subgroups of the cases and the results are summarised in table II.

Although not significantly, the estimated protective efficacy was higher among boys, among those diagnosed before five years of age, among cases identified through contact tracing, and among those who were not admitted to hospital.

Protective efficacy varied but not significantly, according to the type of disease. For all cases except those of hilar tuberculosis the protective efficacy was $68 \%$, for all the cases of hilar tuberculosis it was $16 \%$, and for asymptomatic hilar tuberculosis (defined as those cases diagnosed solely on an abnormal $x$ ray, without clinical symptoms) it was also $16^{\circ}{ }_{0}$. The protective efficacy among all cases except those of asymptomatic hilar tuberculosis was $58^{\circ}{ }_{0}$. In no instance were the estimated protective efficacies significantly different in the various subgroups. 
Table II Percent protective efficacy (PE) in various subgroups.

\begin{tabular}{|c|c|c|c|c|}
\hline \multirow[b]{2}{*}{ All cases } & \multirow{2}{*}{$\begin{array}{l}\text { Number of } \\
\text { case-control } \\
\text { sets }\end{array}$} & \multirow{2}{*}{$\begin{array}{l}P E \\
\left(\begin{array}{l}P \\
o\end{array}\right) \\
49\end{array}$} & \multicolumn{2}{|c|}{$\begin{array}{l}95^{\circ}{ }_{0} \text { Confidence interva } \\
\left(\begin{array}{c}0 \\
0\end{array}\right)\end{array}$} \\
\hline & & & 14 & 70 \\
\hline $\begin{array}{l}\text { Sex: male } \\
\text { female }\end{array}$ & $\begin{array}{l}64 \\
47\end{array}$ & $\begin{array}{l}59 \\
42\end{array}$ & $\begin{array}{l}14 \\
\text { neg }\end{array}$ & $\begin{array}{l}80 \\
75\end{array}$ \\
\hline $\begin{array}{l}\text { Age at diagnosis: } \\
<5 \text { years } \\
\geqslant 5 \text { years }\end{array}$ & $\begin{array}{l}63 \\
48\end{array}$ & $\begin{array}{l}60 \\
11\end{array}$ & $\begin{array}{l}11 \\
\text { neg }\end{array}$ & $\begin{array}{l}82 \\
59\end{array}$ \\
\hline $\begin{array}{l}\text { Site of tuberculosis: } \\
\text { Bone or meningitis } \\
\text { Lungs and pleura } \\
\text { Only lymph node } \\
\text { non-hilar } \\
\text { hilar } \\
\text { Any site except hilar }\end{array}$ & $\begin{array}{r}7 \\
33 \\
71 \\
19 \\
52 \\
59\end{array}$ & $\begin{array}{l}70 \\
76 \\
26 \\
46 \\
16 \\
68\end{array}$ & $\begin{array}{l}\text { neg } \\
28 \\
\text { neg } \\
\text { neg } \\
\text { neg } \\
31\end{array}$ & $\begin{array}{l}98 \\
99 \\
62 \\
85 \\
62 \\
85\end{array}$ \\
\hline $\begin{array}{l}\text { Smear or culture }{ }^{\star}: \\
\text { Positive } \\
\text { Not done }\end{array}$ & $\begin{array}{l}23 \\
79\end{array}$ & $\begin{array}{l}45 \\
61\end{array}$ & $\begin{array}{l}\text { neg } \\
24\end{array}$ & $\begin{array}{l}89 \\
81\end{array}$ \\
\hline $\begin{array}{l}\text { Clinical presentation: } \\
\text { Asymptomatic hilar nodes only } \\
\text { Any excluding asymptomatic } \\
\text { hilar nodes }\end{array}$ & $\begin{array}{l}32 \\
79\end{array}$ & $\begin{array}{l}16 \\
58\end{array}$ & $\begin{array}{l}\text { neg } \\
21\end{array}$ & $\begin{array}{l}71 \\
78\end{array}$ \\
\hline $\begin{array}{l}\text { Case admitted to hospital: } \\
\text { Yes } \\
\text { No }\end{array}$ & $\begin{array}{l}45 \\
66\end{array}$ & $\begin{array}{l}41 \\
53\end{array}$ & $\underset{8}{\text { neg }}$ & $\begin{array}{l}74 \\
77\end{array}$ \\
\hline $\begin{array}{l}\text { Born in district where tuberculosis } \\
\text { was diagnosed }\end{array}$ & 100 & 48 & 9 & 71 \\
\hline $\begin{array}{l}\text { No family history of tuberculosis at } \\
\text { time of birth }\end{array}$ & 101 & 53 & 17 & 74 \\
\hline $\begin{array}{l}\text { Case detected through: } \\
\text { Contact tracing } \\
\text { Other }\end{array}$ & $\begin{array}{l}59 \\
52\end{array}$ & $\begin{array}{l}57 \\
36\end{array}$ & $\begin{array}{l}14 \\
\text { neg }\end{array}$ & $\begin{array}{l}78 \\
73\end{array}$ \\
\hline
\end{tabular}

*Not all sets included, as the remaining group was too small to warrant estimation of protective efficacy
Randomised control trials are usually the method of choice to establish protective efficacy, but where such trials are not appropriate and a retrospective estimate of efficacy is required the case-control method provides an alternative approach. ${ }^{1314} \mathrm{~A}$ weakness of the approach is that vaccinated children may be at a different risk of tuberculosis from unvaccinated children due to reasons other than any protection conferred by the vaccine. In the design and analysis of the study we adjusted for factors that might bias the estimate of protective efficacy, including date of birth, sex, district of birth, ethnic origin, and prior knowledge of a case of tuberculosis in the family, but there may be other confounding factors that were not taken into account, for example socioeconomic status, that will have caused the estimate of protective efficacy to be biased.

The estimated protective efficacy of $49^{\circ}{ }_{0}$ for newborn BCG vaccination against tuberculosis in children of Indian subcontinent origin in the $\mathrm{UK}$ is lower than that estimated for BCG vaccination given to UK schoolchildren (about $80^{\circ}{ }_{0}$ ). Nonetheless the protection associated with newborn vaccination is substantial and our findings vindicate the recommendation to give BCG vaccination to groups at high risk of tuberculosis. It should be noted, however, that many children of Indian subcontinent surname diagnosed with tuberculosis in the UK were excluded from our study because they were not born here, and the vaccination strategy should include children born elsewhere but living in this country. On the other hand, the risk of tuberculous disease in Asian children is declining, ${ }^{10}$ so the effectiveness of the neonatal BCG vaccination programme should be kept under review.

This study would not have been possible without the generous and active collaboration of the District Medical Officer/Medical Officer for Environmental Health, the chest physicians, the local authority Infectious Diseases Clerk, the Chest Clinic, and the child health record staff in each of the participant districts. This study was funded by the Medical Research Council.

The estimate of $49 \%$ protection conferred by BCG vaccination early in life against tuberculosis in children of Asian ethnic origin in this national study is lower than that found $(64 \%)$ in a similar study in Birmingham. ${ }^{12}$ It is possible, however, that some cases in our study may have only been infected rather than having clinical disease. The finding of an enlargement of hilar lymph nodes during contact tracing in a child without clinical symptoms can lead to a change in the child's diagnosis from infection (for which chemoprophylaxis is usually given) to disease. If cases of hilar tuberculosis without clinical symptoms are excluded, the estimate of efficacy we obtain, $58 \%$, is close to that found in Birmingham. In the Birmingham study it was possible to use stricter diagnostic criteria as all of the cases were treated at one centre and cases were excluded who showed no response to treatment based on $x$ ray findings. The clinical records in our study were not complete enough to allow us to do this.

In the present study the efficacy of BCG was lower in girls than in boys, and in cases with enlarged hilar glands than in pulmonary cases, and it decreased with time since vaccination. Although these variations were not statistically significant, it is of note that similar differences, though also not statistically significant, were found in the MRC trial among school children.
1 Hart PDA, Sutherland I. BCG and vole vaccines in the prevention of tuberculosis in adolescence and early adult
life: final report to the Medical Research Council. $B M F$ 1977; ii: 293-5.

2 British Thoracic Association. Present effectiveness of BCG vaccination in England and Wales. Tubercle 1975; 56: 129-37.

3 British Thoracic Association. Effectiveness of BCG vaccination in Great Britain in 1978. Br f Chest Dis 1980; 74: $215-27$

4 DHSS/SHHD/WO. BCG vaccination. Memo BCG Revised 1972. Edinburgh: HMSO Press.

5 Tuberculosis Prevention Trial. Trial of BCG vaccines in South India for tuberculosis prevention: first report. Bull

6 ten Dam HG, Hitze K. Does BCG vaccination protect the ten Dam HG, Hitze K. Does BCG vaccination protect the newborn and young infant? Bull WHO 1980; 58: $37-41$. Fine PEM. BCG vaccination against leprosy. Br Med Bull 1988; 44: 691-703. Curtis HM, Leck I, Bamford FN. Incidence of childhood tuberculosis after neonatal BCG vaccination. Lancet 1984;
i: $145-8$. i: $145-8$

9 Medical Research Council. The geographical distribution of tuberculosis notifications in a national survey of England

10 Medical Research Council Tuberculosis and Chest Diseases Unit. Tuberculosis in children: a national survey of 1983. Arch Dis Child 1988; 63: 266-276.

11 Epidemiologic graphics estimation and testing package. Corporation, 1989.

12 Packe GE, Innes JA. Protective effect of BCG vaccination in infant Asians: a case-control study. Arch Dis Child 1988; 63: infant Asia Technical Report Series No. 651. Geneva: WHO, 1980. 14 Smith PG. Retrospective assessment of the effectiveness of BCG vaccination against tuberculosis using the casecontrol method. Tubercle 1983; 62: 23-35. South India for tubercul and Wales (1978-9). Tubercle 1982; 63: 75-88. Washington: Statistics and Epidemiology Research

13 World Health Organization. Vaccination against tuberculosis. 